Research Article

\title{
Numerical and Experimental Investigation of the Effect of Cavitation on Dual Clearance Squeeze Film Damper
}

\author{
Zhaojun Feng, ${ }^{1}$ Guihuo Luo $\mathbb{D},{ }^{1}$ Hai Yang, ${ }^{2}$ Wangqun Deng, ${ }^{2}$ Wei Chen $\mathbb{D},{ }^{1}$ \\ and Cheng Shen ${ }^{1}$ \\ ${ }^{1}$ College of Energy and Power Engineering of Nanjing University of Aeronautics and Astronautics, \\ Key Laboratory of Jiangsu Aviation Powerplant, Nanjing, 210001, China \\ ${ }^{2}$ AECC Hunan Aviation Powerplant Research Institute, Key Laboratory of Aero-engine Vibration Technology, \\ Aero Engine Corporation of China, Zhuzhou, 412002, China
}

Correspondence should be addressed to Guihuo Luo; ghluo@nuaa.edu.cn

Received 9 June 2021; Revised 12 August 2021; Accepted 31 August 2021; Published 13 September 2021

Academic Editor: Hulun Guo

Copyright (c) 2021 Zhaojun Feng et al. This is an open access article distributed under the Creative Commons Attribution License, which permits unrestricted use, distribution, and reproduction in any medium, provided the original work is properly cited.

\begin{abstract}
A new dynamic model is developed for the dual clearance squeeze film damper (DCSFD) considering the effect of cavitation in this paper. The relationship between the eccentricities of the inner and outer films is achieved based on the equations of motion. The Reynolds equation and Rayleigh-Plesset equation are employed to describe the kinetic properties of DCSFD and the cavitation effect of film, respectively. Under the assumption of compressible fluid, the pressure distribution of DCSFD is finally obtained by the numerically iterative method. The film pressure distribution in the outer layer (including the positive and negative pressure zones) obtained from the experimental test agrees well with the numerical prediction, which verifies the validity of the proposed numerical model. In Section 5, the effects of oil temperature, inlet pressure, eccentricity, and whirling frequency on the cavitation in the film are investigated systematically and experimentally. The experimental results indicate that cavitation mainly affect the pressure in the negative pressure zone of the inner and outer film of DCSFD, but has little influence on the pressure in the positive pressure zone. The area of cavitation increased with eccentricity; when the inner eccentricity reached 0.1 or above, the area near the injection hole of film also generated a small zone of negative pressure. The numerical model and the experimental results in this paper are valuable for further research and engineering applications of DCSFD.
\end{abstract}

\section{Introduction}

The squeeze film damper (SFD) has attracted much attention for its good performance in vibration mitigation. In recent years, the relevant studies have focused on the following issues: the characteristics of nonlinear vibrations of a rotor supported on SFD [1,2], methods of modeling the SFD by considering the effects of fluid inertia [3-7], and the cavitation, the fluid-structure interference, and the structural innovation [8-11]. For example, Chen et al. [1] found that the rotor-SFD system was sensitive to the ratio of two excitation frequencies acted on the rotor system and the influence of fluid inertia becomes greater with the Reynolds number [5]. Lu et al. investigated the influence of the size of clearance of end seals on the damping characteristic of ISFD.
It was observed that the damping of ISFD increased significantly with the tightness of end seals [11].

The DCSFD studied in this paper is obtained by improving the structure of the SFD.

In 1985, the DCSFD was introduced by Fleming [12] on the basis of traditional SFD. The DCSFD was proposed to prevent fatigue in an SFD in a rotor-SFD system. A number of studies [12-19] have been dedicated to the DCSFD in the last 50 years. Moraru et al. [13-16] constructed a numerical model for a rotor supported on the DCSFD, and they presented results obtained while the inner sleeve is released and both oil films are operational. Different from rigid supported housing, Rezvani and Hahn [17] proposed a DCSFD with a spring support which can avoid the jump and aperiodic response of the rotor. Zhou et al. [18, 19] deduced 
two Reynolds equations of the DCSFD to determine the unbalance response of the rotor-DCSFD system. The results indicated that the bifurcation of the rotor system can be inhibited when it is supported by the DCSFD. The above studies show that DCSFD has a promising future in aeroengine vibration mitigation. The above research indicates that there is considerable prospect for the application of the DCSFD to aeroengines.

Cavitation is one of the most important factors affecting the effectiveness of squeeze film dampers, and much work has been done in this area. For example, Hibner and Bansal [20] found that the deviation in terms of film pressure between simulations and experiments became unacceptable as the cavitation extended around the region of the film. Feng and Hahn [21] concluded that once the cavitation has formed, it cannot dissolve completely in the film again; then, the oil will become a compressible two-phase fluid. For the influence of the cavitation, multiple studies have been carried out by Jung et al. [22, 23], and it was found that cavitation affects the negative as well as positive pressure regions. The expansion in the negative pressure region sharply slows down in case of cavitation; then, the damping and inertia coefficients of SFD decreased significantly. Kodama et al. [24] built a centered SFD test rig to observe the conditions of rupture of the cavitation. Bonello et al. [25] claimed that the region of expansion of the cavitation increases with the static eccentricity or unbalance loads. Xing et al. [26-28] modeled the SFD based on three-dimensional Navier-Stokes equations and employed a homogeneous cavitation model to simulate a quasi-static cavitation process. Jung [29] found that cavitation was suppressed as the oil injected pressure increased. Méndez et al. [30] modeled the SFD in a two-phase fluid consisting of the oil and ingested air based on Andre's model, in which the volume of the latter was a function of the L/R ratio. Arghir and Bonneau [31] built a dynamic pressure equation for the SFD based on the Rayleigh-Plesset equation which can consider the influence of cavitation surface stress, damping, and inertia effect. Younan et al. [32] deduced the Reynolds equation of the SFD by considering the effect of ingested air. They proposed the viscosity and density of oil as the functions of volume fraction of the air/oil and modeled two-phase fluid density as a function of bubble diameter that changed according to the nonlinear transient film force. Heidari and Ashkooh [33] investigated the stability and bifurcation characteristic of the rotor-SFD system. As cavitation formed, the increasing stiffness-related asymmetry of the SFD film enhanced the likelihood of instability of the rotor-SFD system. Gehannin et al. distinguish the vapor cavitation from air ingestion while building a SFD cavitation model, in which film pressure was governed by the Reynolds equation; vapor cavitation was modeled based on the Rayleigh-Plesset equation and air ingestion was given by the volume-of-fluid (VOF) method [34]. Laurentiu claimed that the SFD film could be continued while oil inlet and outlet pressure are all significantly above the surrounding atmospheric pressure [35]. Fan and Behdinan developed the models of incompressible and compressible SFD films by using the linear complementarity problem (LCP) method where the latter model is superior if the bulk modulus of elasticity is considered [36].
From the literature review, it is found that few of existing studies concentrated on the influence of cavitation on the DCSFD, which delivers better performance in terms of suppressing vibration than traditional SFD. In this paper, a dynamic numerical model is developed for the DCSFD considering the effect of cavitation. Firstly, a relationship between eccentricity of the inner and outer films is established according to equations of motion. Then, the DCSFD model itself will be established based on Reynolds equations and eccentricity relationship. Furthermore, the Rayleigh-Plesset equation is employed to describe the cavitation effect. The DCSFD model and Rayleigh-Plesset equations are solved simultaneously to obtain final pressure distribution cavitation of the film. Meanwhile, a test rig of DCSFD film characteristic is constructed and some experiments are carried out.

\section{Model of DCSFD}

A structure diagram of DCSFD is shown in Figure 1.

Before modeling the cavitation, the DCSFD should be modeled, that is, the relationship between eccentricity of the inner and outer films and the distribution of pressure should be presented. The floating ring and journal whirl while the DCSFD was working, where the latter whirls actively and the former passively. There is a phase difference between the journal and the floating ring and the eccentricity of the inner and outer film is not the same. In order to determine the pressure distribution of the inner film, it is necessary to obtain the relative eccentricity first.

To simplify our modeling, three necessary assumptions are made:

(1) The whirling orbits of the journal and the floating ring are circular; their whirling frequency is equal

(2) The gravitational influence of the floating ring is ignored

(3) The floating ring does not deform while whirling

The force acting on the floating ring is provided in Figure 2, where

$e_{1}$ : the eccentric distance of the journal

$e_{2}$ : the eccentric distance of the floating ring

$e_{3}$ : the relative eccentric distance between the journal and the floating ring

$\gamma$ : the phase difference between the journal and the floating ring

$\theta$ : the angle between the direction of the inner film in the minimum thickness and the outer film in the maximum thickness

$F_{r 1}$ : the radial force of the inner film

$F_{t 1}$ : the circumferential force of the inner film

$F_{r 2}$ : the radial force of the outer film

$F_{r 2}$ : the circumferential force of the outer film

The forces $F_{t 1}, F_{r 1}, F_{t 2}$, and $F_{r 2}$ act on the floating ring with the inner and outer film, where the first two and latter two forces belong to driving force and the passive force, 


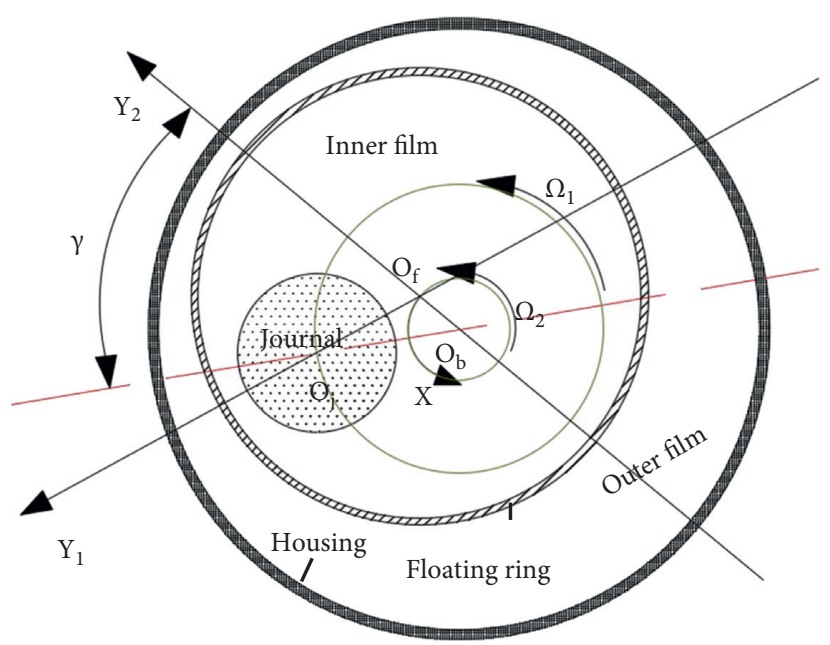

FIgUre 1: Schematic model of the DCSFD.

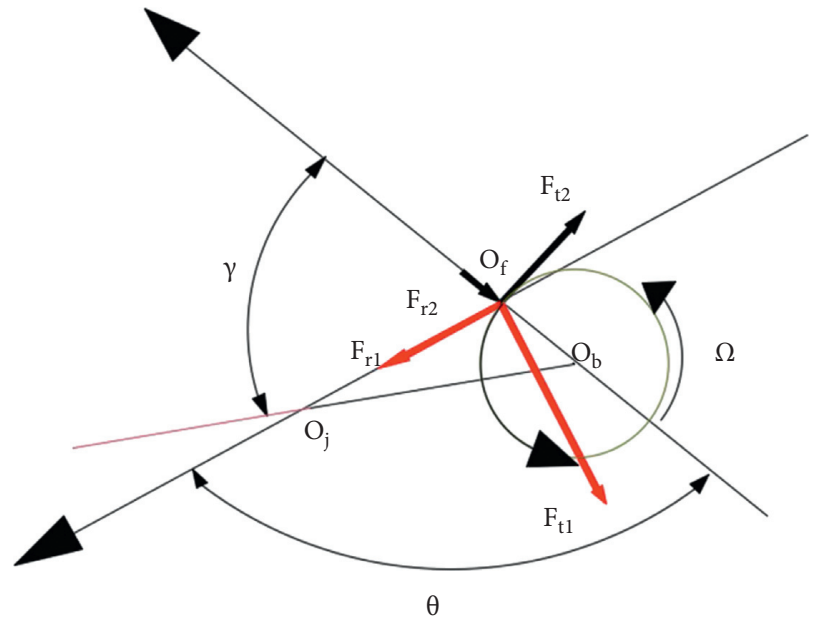

FIgURE 2: Force diagram of the floating ring.

respectively. Based on Newton's second law, the equations of motions are represented by equations (1) and (2):

$$
\begin{gathered}
F_{t 1} \cos \left(\theta-\frac{\pi}{2}\right)-F_{r 1} \cos (\pi-\theta)+F_{r 2}=m_{f} \Omega^{2} e_{2}, \\
F_{r 1} \sin (\pi-\theta)+F_{t 1} \sin \left(\theta-\frac{\pi}{2}\right)=F_{t 2},
\end{gathered}
$$

where $F_{t 1}$ and $F_{r 1}$ are determined by $\varepsilon_{3}$ and $F_{t 2}$ and $F_{r 2}$ were determined by $\varepsilon_{2}$. Equations (1) and (2) could be solved in a rotating reference frame. The relation among $\varepsilon_{1}, \varepsilon_{2}$, and $\varepsilon_{3}$ is given as

$$
\varepsilon_{3}^{2}=\varepsilon_{1}^{2}+\frac{\varepsilon_{2}^{2}}{r_{t}^{2}}-\frac{2 \varepsilon_{1} \varepsilon_{2} \cos \gamma}{r_{t}},
$$

where $r_{t}$ was the thickness ratio between the inner and outer film, that is,

$$
r_{t}=\frac{C_{1}}{C_{2}}
$$

The angle $\theta$ could be obtained by the cosine theorem according to equations (1) and (2):

$$
\theta=\arccos \frac{e_{2}^{2}+e_{3}^{2}-e_{1}^{2}}{2 e_{2} e_{3}} .
$$

To obtain the inner and outer film forces of the DCSFD, we need to model their pressure distributions. There is a clearance between the floating ring and the end seal ring, as shown in Figure 3. It results in the increase of the flow rates and decrease of the film pressure. The Reynolds equations of the inner and outer film of DCSFD are given in equations (6) and (7):

$$
\begin{aligned}
& \frac{1}{R_{1}^{2}} \frac{\partial}{\partial \theta_{1}}\left(\frac{\rho h_{1}^{3}}{\mu} \frac{\partial p_{1}}{\partial \theta_{1}}\right)+\frac{\partial}{\partial Z}\left(\frac{\rho h_{1}^{3}}{\mu \eta} \frac{\partial p_{1}}{\partial Z}\right)=12 \frac{\partial \rho h_{1}}{\partial t}, \\
& \frac{1}{R_{2}^{2}} \frac{\partial}{\partial \theta_{2}}\left(\frac{\rho h_{2}^{3}}{\mu} \frac{\partial p_{2}}{\partial \theta_{2}}\right)+\frac{\partial}{\partial Z}\left(\frac{\rho h_{2}^{3}}{\mu \eta} \frac{\partial p_{2}}{\partial Z}\right)=12 \frac{\partial \rho h_{2}}{\partial t},
\end{aligned}
$$

where $\eta$ is the coefficient of pressure loss. 


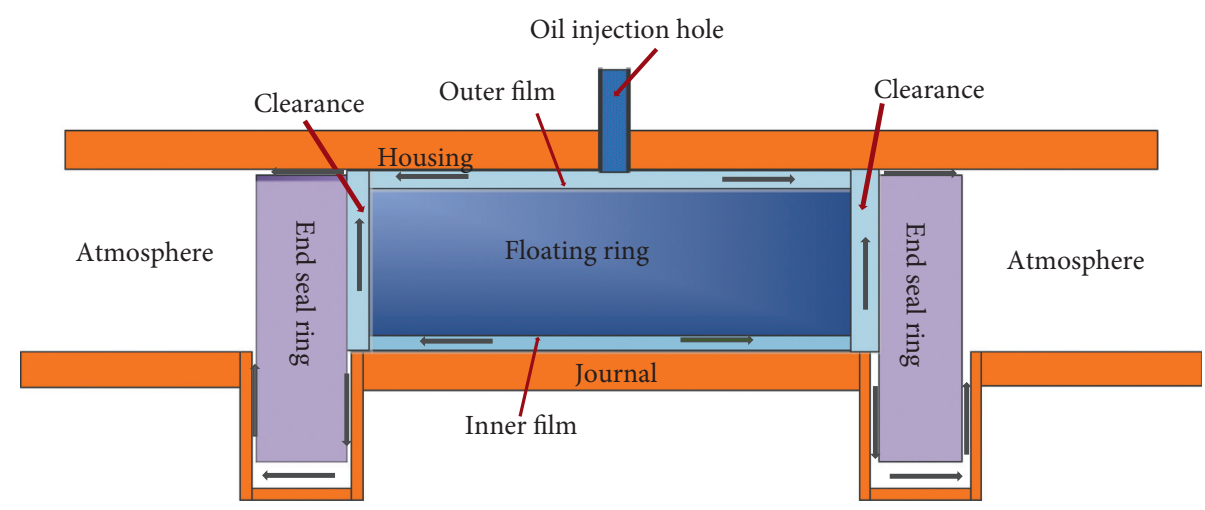

FIgURE 3: The clearance between floating ring and end seals.

Because the pressure loss is too complex to be theoretically analyzed for turbulence, $\eta$ is obtained in its empirical range in this paper:

$$
0.2<\eta<0.3 \text {. }
$$

Considering cavitation effect, the negative pressure zone will also have an effect on the film pressure, so the DCSFD film force could be obtained by equations (9)-(12):

$$
\begin{aligned}
& F_{r 1}=\int_{-L_{f} / 2}^{L_{f} / 2} \int_{0}^{2 \pi} p_{1}\left(\theta_{1}, Z\right) R_{1} \mathrm{~d} \theta_{1} \mathrm{~d} Z \cos \theta_{1}, \\
& F_{r 1}=\int_{-L_{f} / 2}^{L_{f} / 2} \int_{0}^{2 \pi} p_{1}\left(\theta_{1}, Z\right) R_{1} \mathrm{~d} \theta_{1} \mathrm{~d} Z \sin \theta_{1}, \\
& F_{r 1}=\int_{-L_{f} / 2}^{L_{f} / 2} \int_{0}^{2 \pi} p_{2}\left(\theta_{2}, Z\right) R_{2} \mathrm{~d} \theta_{2} \mathrm{~d} Z \cos \theta_{2}, \\
& F_{r 1}=\int_{-L_{f} / 2}^{L_{f} / 2} \int_{0}^{2 \pi} p_{2}\left(\theta_{2}, Z\right) R_{2} \mathrm{~d} \theta_{2} \mathrm{~d} Z \sin \theta_{2},
\end{aligned}
$$

where $L_{f}$ is the width of the floating ring.

\section{Model of Cavitation}

In the zone of negative pressure of the inner and outer film of DCSFD, the vapor cavitation occurs when the pressure is reduced below the saturated vapor pressure of the film. There is less gas cavitation in the film in the zone of negative pressure because the DCSFD has two end seals.

Previous studies [31, 34, 37] show that the RayleighPlesset equation can describe the process of cavitation growth successfully and predict the range of the zone of negative pressure accurately of SFD. Following the same strategy, the cavitation in the negative pressure zone of DCSFD is modeled based on the Rayleigh-Plesset equation in this paper.

Gehannin proposed the complete Rayleigh-Plesset equation based on the past research [34]:

$$
\frac{P_{B}-P_{\infty}(t)}{\rho_{L}}-\frac{4 \nu_{L}}{R} \dot{R}-\frac{2 S}{\rho_{L} R}-\frac{4 \kappa}{\rho_{L} R^{2}} \dot{R}=R \ddot{R}+\frac{3}{2} \dot{R}^{2}
$$

where $P_{\infty}(t)$ is the pressure of the film around the bubble, $\rho_{L}$ is the density of the film around the bubble, $R(t)$ is the radius of the bubble, $\nu_{L}$ is the viscosity of the film around the bubble, $S$ is the surface tension of the bubble, and $\kappa$ is the dilatational viscosity of the bubble.

Equation (13) describes the relationship among the rate of change for radius of the bubble, liquid pressure, viscosity, surface pressure, and dilatational viscosity in a liquid. The left side of equation (13) represents the difference between the internal and external pressure of the bubble, damping, surface stress, and dilatational viscosity.

Assuming atmospheric pressure is $P_{0}$, the additional pressure $P_{s}$ will be attached to the surface bent at the bubbles, when they appear in the film. According to Kelvin's formula, the total pressure is

$$
P=P_{s}+P_{0} \text {. }
$$

The relation between additional pressure $P_{s}$ and the radius of curvature $R$ can be obtained according to the Young-Laplace equation:

$$
P_{s}=\frac{2 S}{R}
$$

The gas in the DCSFD film area can be divided into vapor cavitation and gas cavitation. Thus, the pressure of bubbles in the fluid can be understood as synthesized by the pressures of vapor and gas cavitation:

$$
P_{B}=\frac{p_{0} R_{a}^{3}}{R^{3}}+p_{v}=\left(p_{a}+\frac{2 S}{R_{a}}-p_{v}\right)\left(\frac{R_{a}}{R}\right)^{3}+p_{v},
$$

where $R_{a}$ is radius of reference bubble and $p_{v}$ is vapor pressure.

The volume ratio of the bubble to the entire area of the film can be obtained by [34]

$$
\alpha(\theta, z, t)=\frac{\alpha_{a}}{\alpha_{a}+\left(1-\alpha_{a}\right) R_{a}^{3} / R^{3}},
$$

where $\alpha_{a}$ is the reference volume ratio and $R_{a}, \alpha_{a}$, and $\alpha_{a}$ are assigned values based on experience [34].The density and viscosity of two-phase flow can be obtained according to $\alpha$ [34]: 


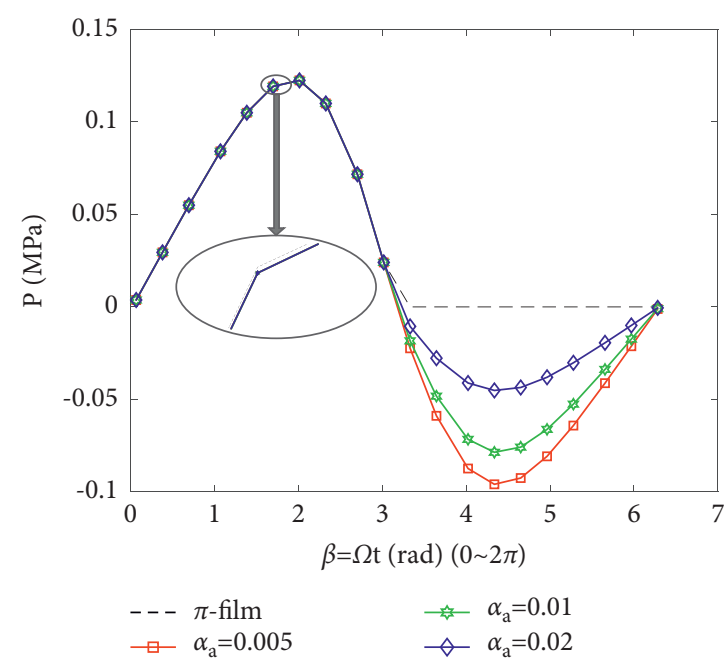

(a)

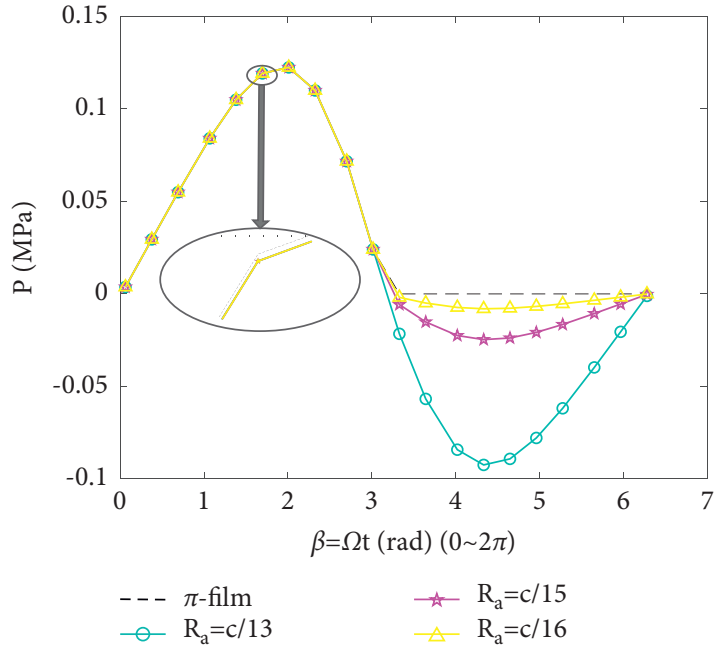

(b)

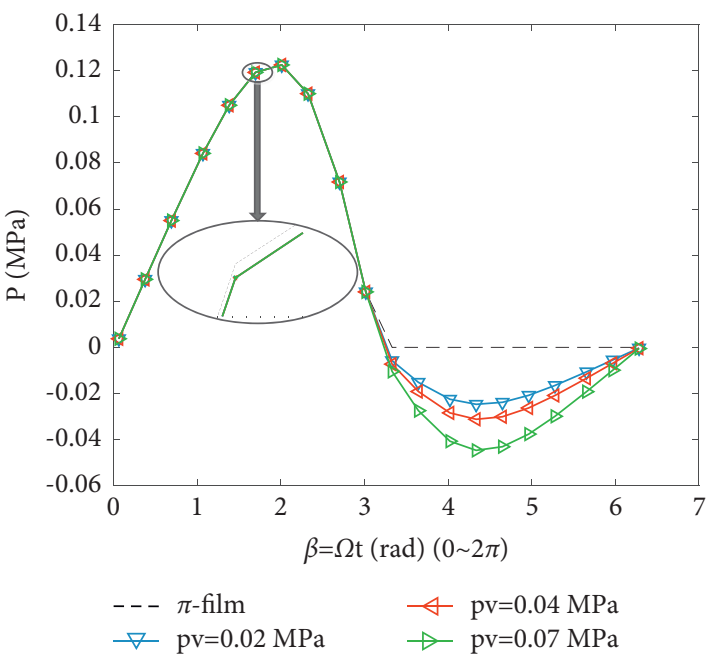

(c)

Figure 4: The effects of $R_{a}, p_{v}$, and $\alpha_{a}$ on inner pressure. (a) $R_{a}=C_{1} / 15, p_{v}=0.02 \mathrm{MPa}$, (b) $p_{v}=0.02 \mathrm{MPa}, \alpha_{a}=0.01$, and (c) $R_{a}=C_{1} / 15, \alpha_{a}=0.01$.

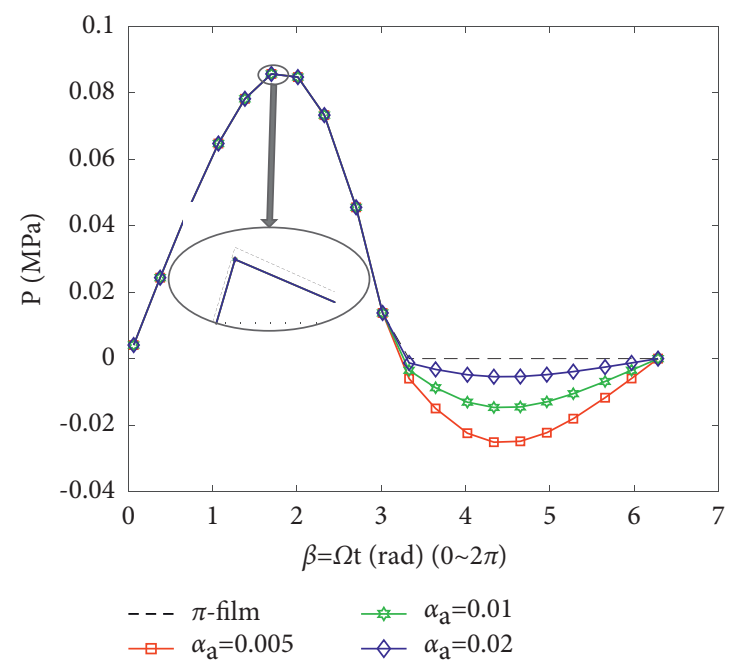

(a)

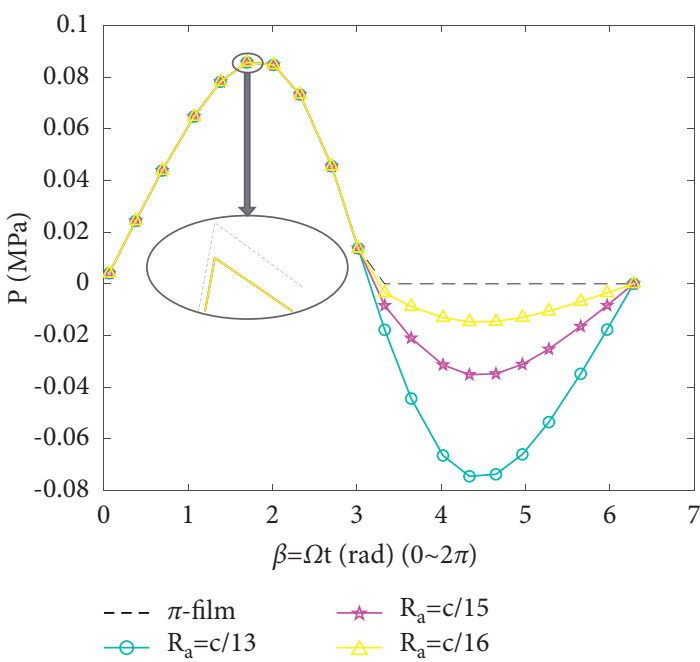

(b)

Figure 5: Continued. 


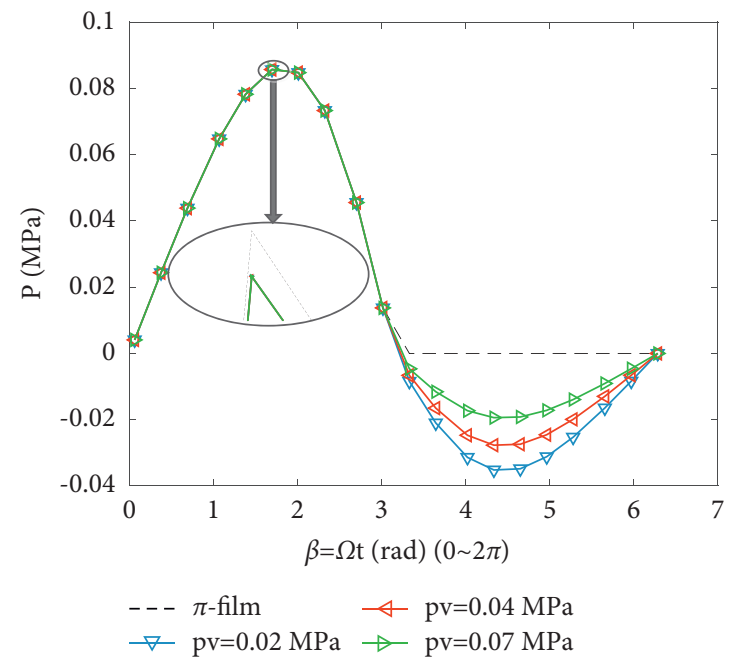

(c)

Figure 5: The effects of $R_{a}, p_{v}$, and $\alpha_{a}$ on outer pressure. (a) $R_{a}=C_{2} / 15, p_{v}=0.02 \mathrm{MPa}$, (b) $p_{v}=0.02 \mathrm{MPa}, \alpha_{a}=0.01$, and (c) $R_{a}=C_{1} / 15, \alpha_{a}=0.01$.

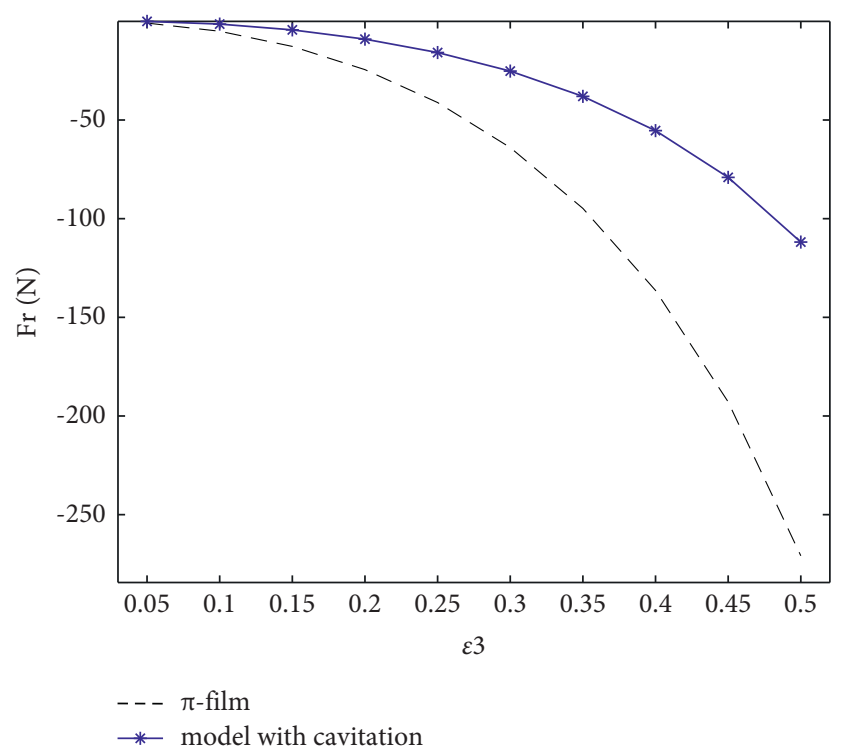

(a)

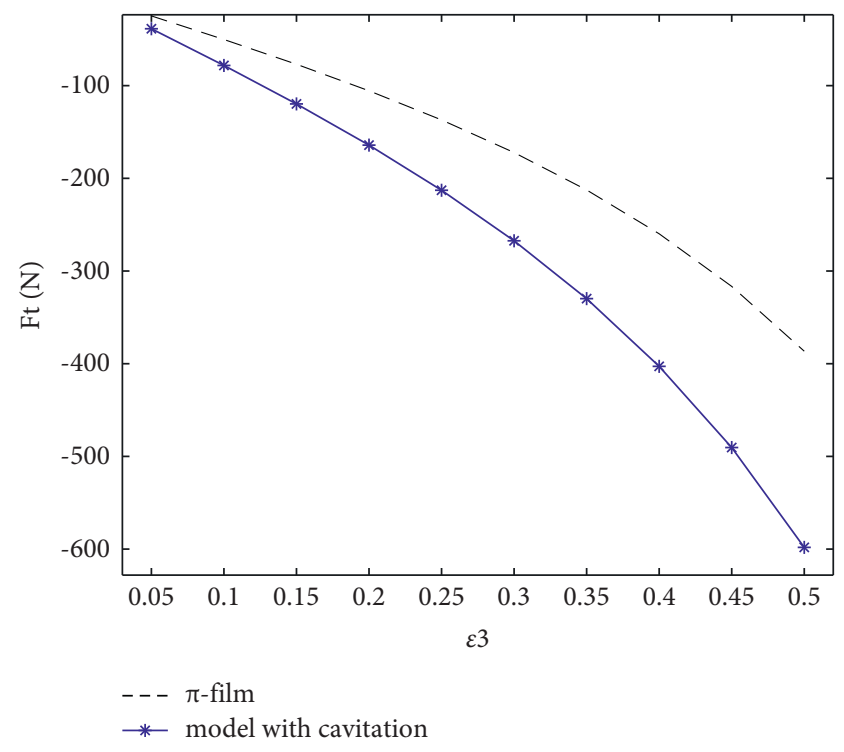

(b)

FIgURE 6: Continued. 


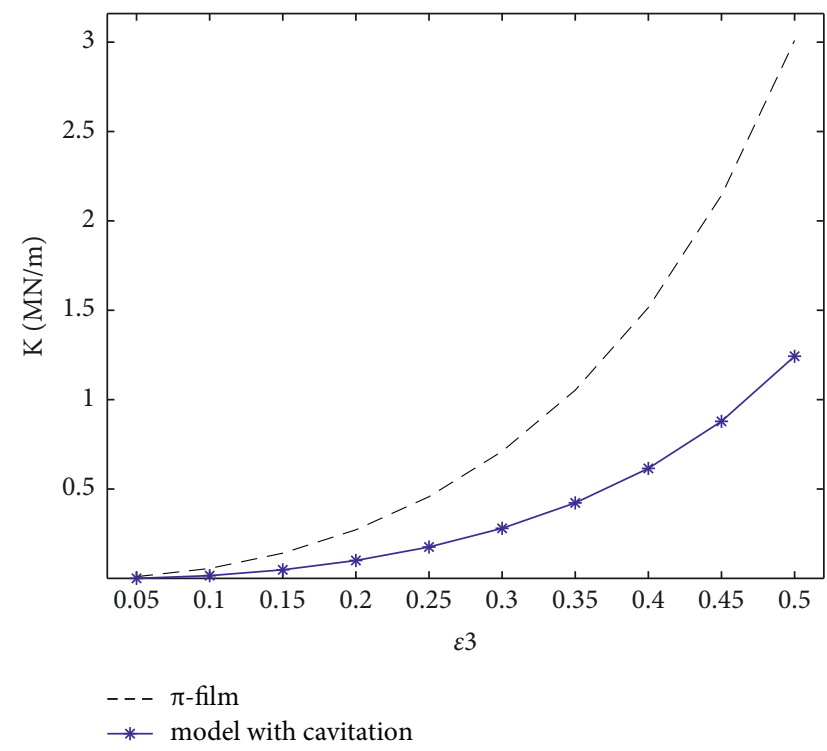

(c)

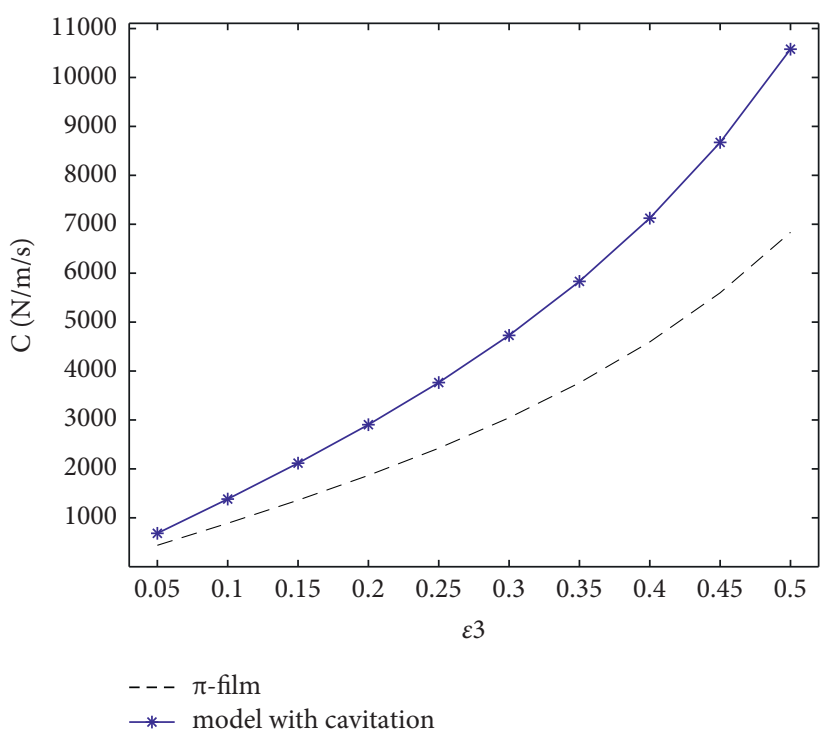

(d)

Figure 6: The influence of cavitation on the DCSFD. (a) Radial film force. (b) Circumferential film force. (c) Film stiffness. (d) Film damping.

$$
\begin{aligned}
& \rho=(1-\alpha) \rho_{L}+\alpha \rho_{G} \approx(1-\alpha) \rho_{L} \\
& \mu=(1-\alpha) \mu_{L}+\alpha \mu_{G} \approx(1-\alpha) \mu_{L}
\end{aligned}
$$

Assuming that the initial volume ratio and radius of the bubble are the same as the reference bubble,

$$
\begin{aligned}
& \alpha_{0}=\alpha_{a} . \\
& R_{0}=R_{a} .
\end{aligned}
$$

The solution of the film pressure distribution could be carried out by solving equations (6) and (7), and the cavitation distribution could be obtained by solving equation (13) in turn to obtain the density and viscosity of the twophase flow.

The Rayleigh-Plesset (equation (13)) is solved by the fourth-order Runge-Kutta method, and the transient Reynolds equations (equations (6) and (7)) are solved by the differential method. To obtain a more accurate initial value to improve the efficiency of the solving process, the initial inner and outer pressure distribution starting differential iteration is obtained using the transient analytic expression [39]:

$$
p(z, \alpha, t)=-\frac{6 \mu L^{2} \omega}{C_{1}^{2}} \frac{\varepsilon_{3} \sin (\omega t-\alpha)}{\left[1-\varepsilon_{3} \cos (\omega t-\alpha)\right]^{3}}\left(\frac{1}{4}-\left(\frac{Z}{L_{f}}\right)^{2}\right) .
$$

\section{The Effect of Cavitation on DCSFD}

The parameters of the DCSFD designed in this paper are $L=12.5 \mathrm{~mm}, C_{1}=0.18 \mathrm{~mm}, C_{2}=0.16 \mathrm{~mm}, R=39 \mathrm{~mm}$, $\rho=997.5 \mathrm{~kg} / \mathrm{m}^{3}$, and $\mu=0.0398 \mathrm{~Pa}, \mathrm{~s}$. The whirling frequency is assumed to be $100 \mathrm{~Hz}$, and all parameters of the film correspond to an inlet oil temperature: $27^{\circ} \mathrm{C}$.

4.1. Influence of the Parameter $R_{a}, p_{v}$, and $\alpha_{a}$. When $\varepsilon_{1}=0.2$, $\varepsilon_{3}=0.12$, and $\varepsilon_{2}=0.087$ through iterative calculations, in an aeroengine, the journal of the rotor is influenced by the force of the inner film of the DCSFD. We thus investigate the effects of cavitation on the distribution of the inner film.

The properties of cavitation is reflected mainly by $R_{a}, p_{v}$, and $\alpha_{a}$, and the influence of cavitation is researched by the control variable method.

Figures 4 and 5 indicate the simulation result of transient film pressure and the monitoring point phase $\alpha=180^{\circ}$; in this way, the negative pressure zone was between $\pi-2 \pi$. Figures 4 and 5 show that $R_{a}, p_{v}$, and $\alpha_{a}$ have significant influence on the distribution of inner and outer pressure, and the influence on inner film pressure is little different from outer film pressure. With an increase in $\alpha_{a}$ and decrease in $R_{a}$ and $p_{v}$, the pressure tends to be zero and the distribution of film pressure is close to $\pi$ film in the area of the negative pressure zone. The film in the area of negative pressure will be directly torn to form a hole. Thus, the film does not exhibit secondphase flow. When considering the cavitation effect, the pressure in the zone of the positive pressure is slightly lower than the $\pi$ film, but the difference is small enough to be ignored. Jung and Andres have concluded that vapor cavitation can affect the zones of negative and positive pressure of the SFD based on the experimental observations [22, 23]. Their results have been verified once again in this paper.

The outer film has a more pronounced trend toward the $\pi$ film than the inner film. The outer film pressure is lower than inner pressure and the cavitation in the inner film will gush out into the outer film. This phenomenon has also been observed in the experiment section of this paper. 


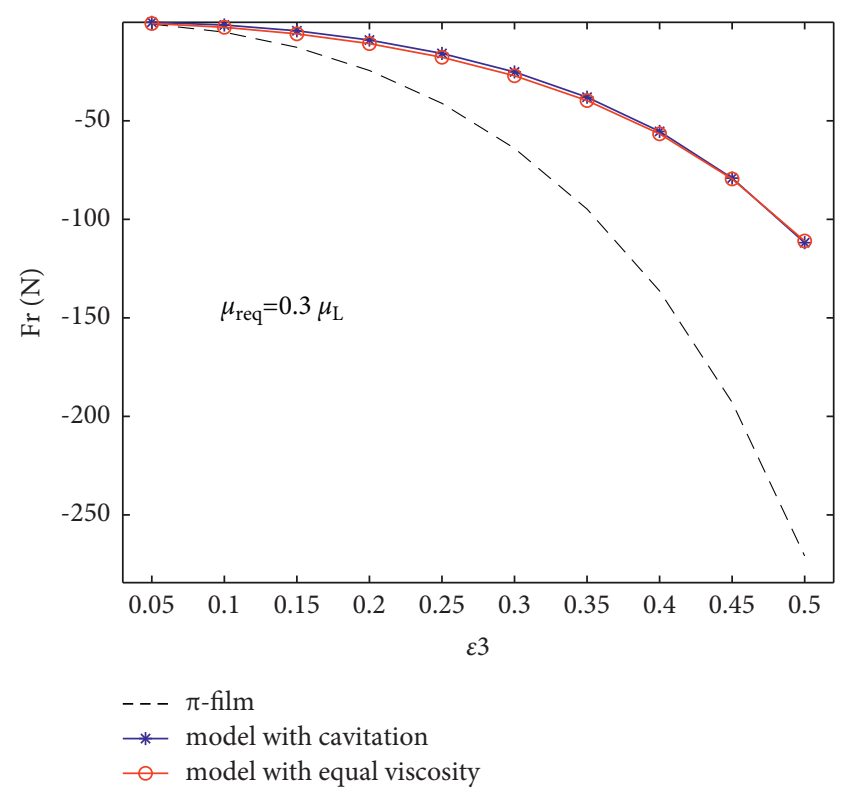

(a)

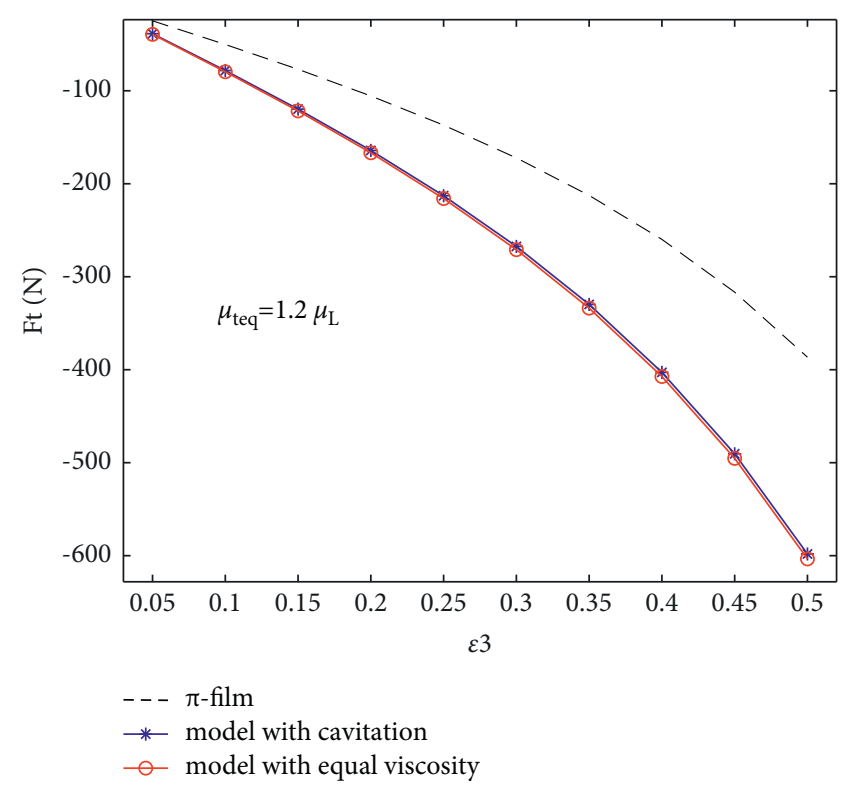

(b)

FIgURE 7: The fitted force of the inner film. (a) Radial film force. (b) Circumferential film force.

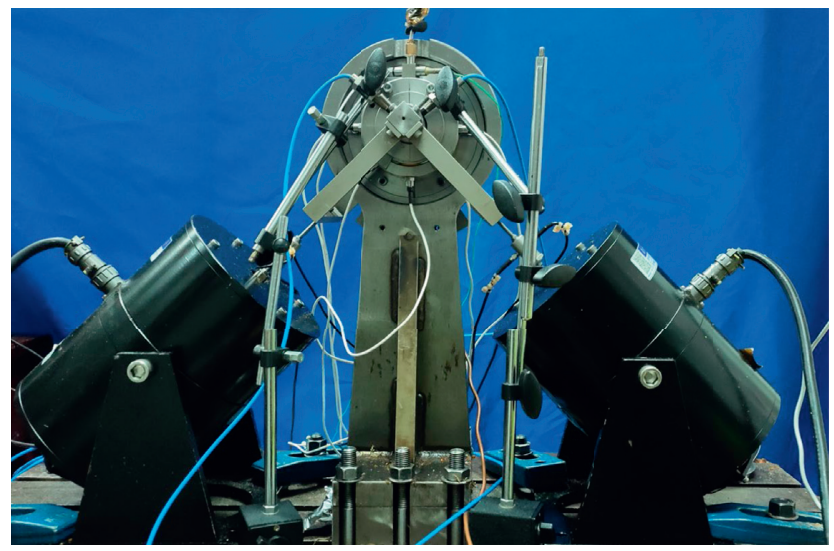

FIGURE 8: Bidirectional excitation test rig.

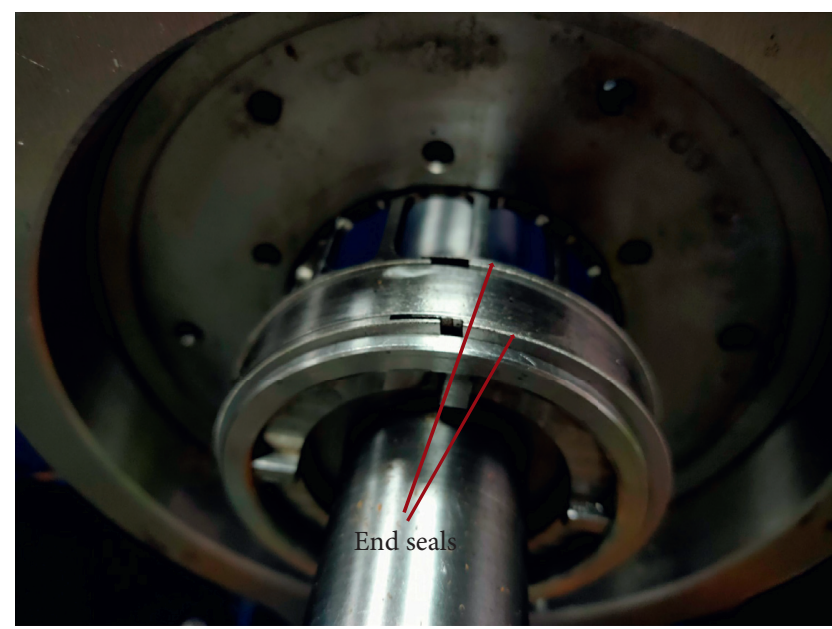

Figure 9: End seals' ring.

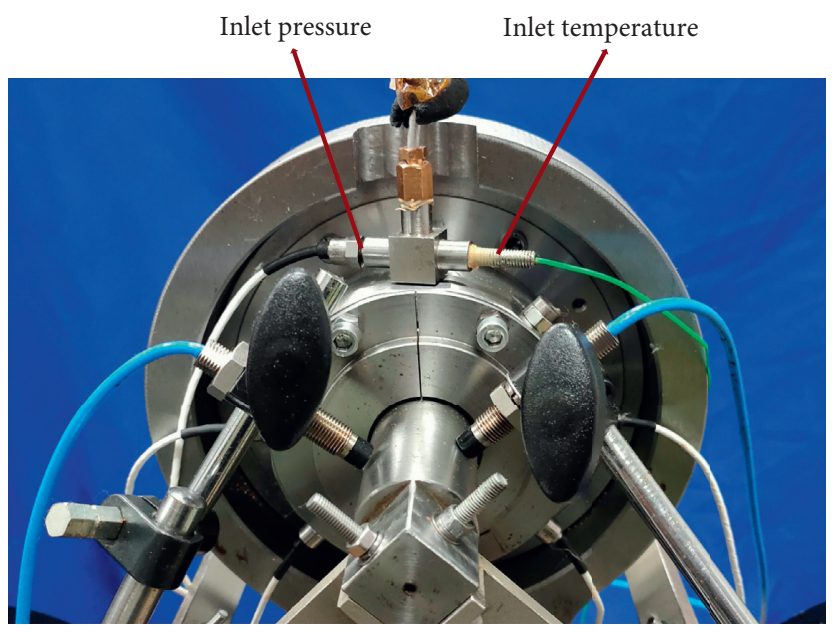

FIGURE 10: Inlet pressure and temperature. 


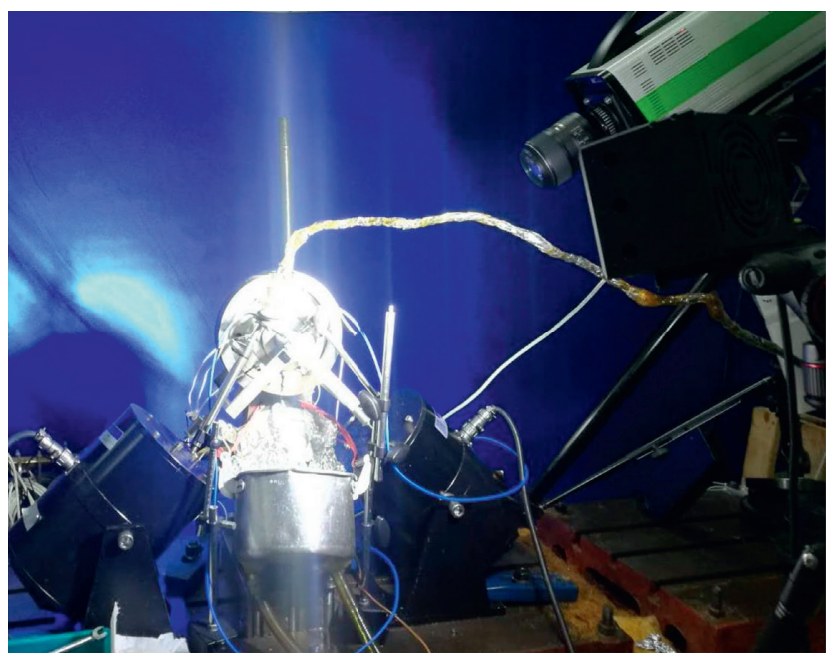

Figure 11: High-speed photography.

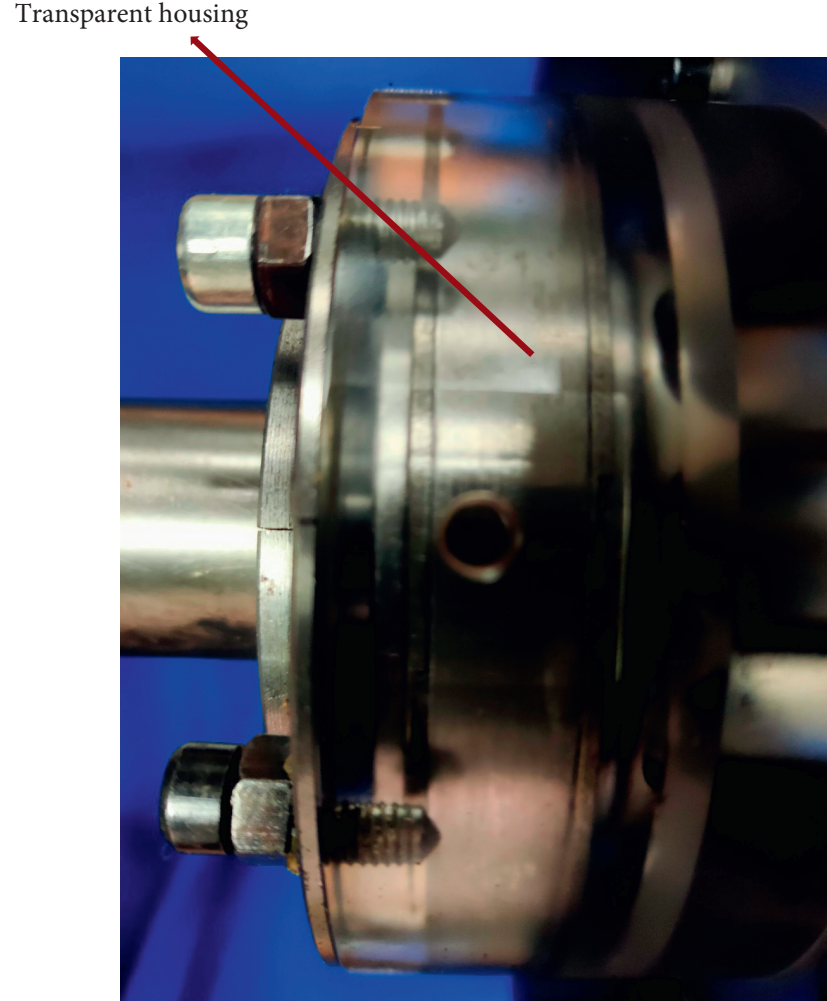

(a)

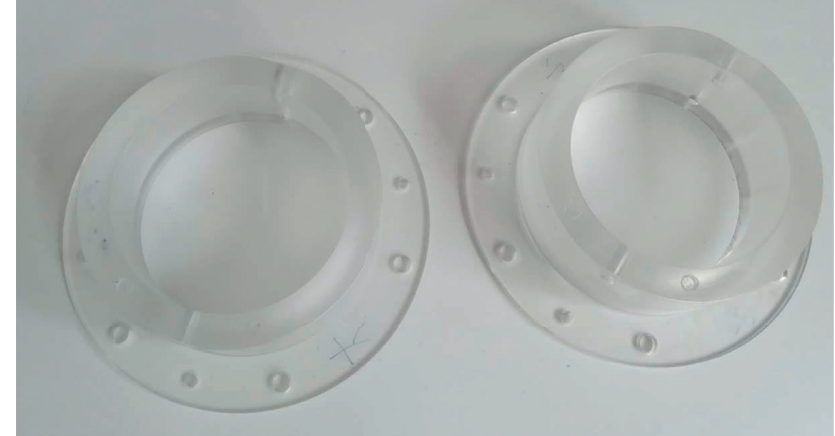

(b)

FIgURE 12: The transparent housing.

4.2. Influence of Cavitation on Film. When $R_{a}=C_{1} / 15, p_{v}=$ $0.02 \mathrm{MPa}$, and $\alpha_{a}=0.01$ the curves of how the film force, film stiffness, and film damping vary with $\varepsilon_{3}$ are shown in Figure 6.

Figure 6 shows that the radial film force and film stiffness decrease as the cavitation effect increases, while the circumferential film force and film stiffness increase. For the journal, the two components of film pressure have the same direction along circumferential direction but have opposite direction along radial direction in both positive and negative pressure zone.

All curves remain similar in shape indicating that the film force, film stiffness, and damping vary in a similar pattern with eccentricity whether or not cavitation effects are considered.

For the DCSFD inner film, the expression of the film force is shown in (23) based on the short-bearing hypothesis: 


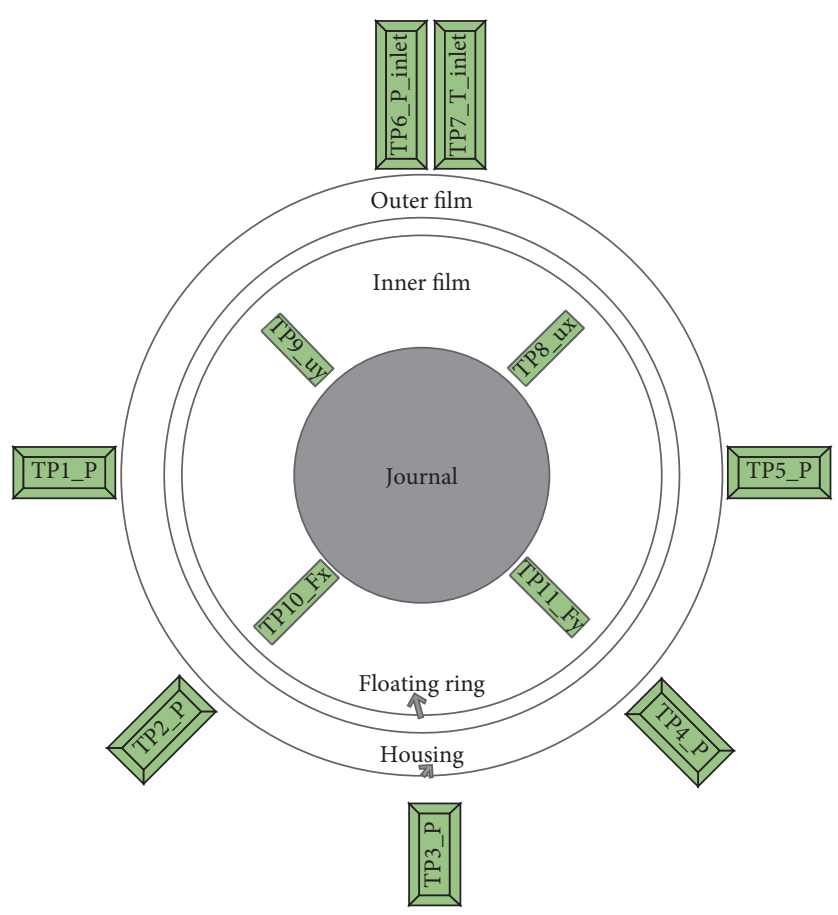

FIgURE 13: The distribution of displacement and pressure sensors.

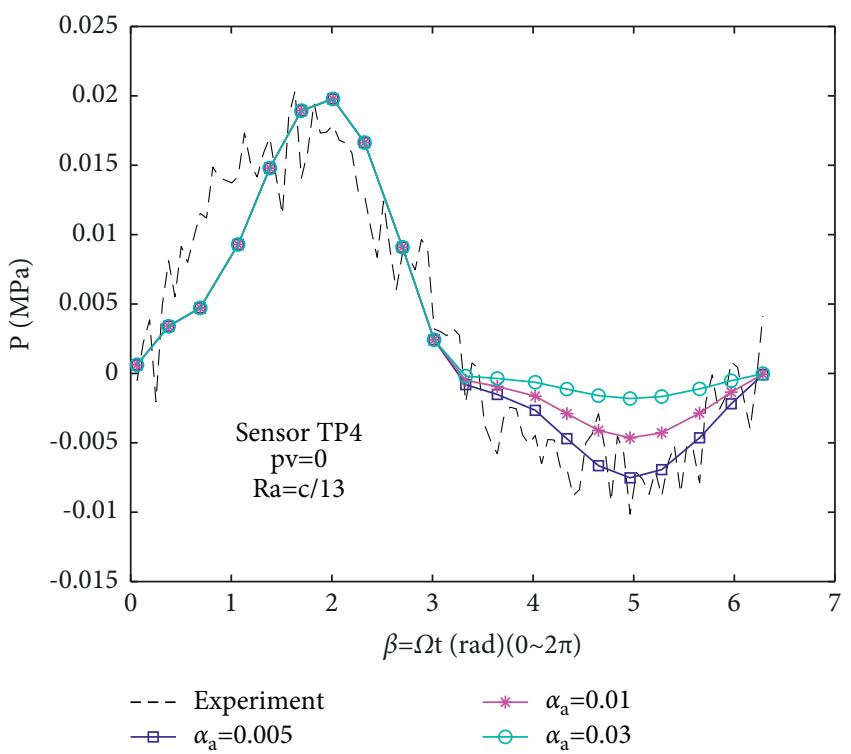

(a)

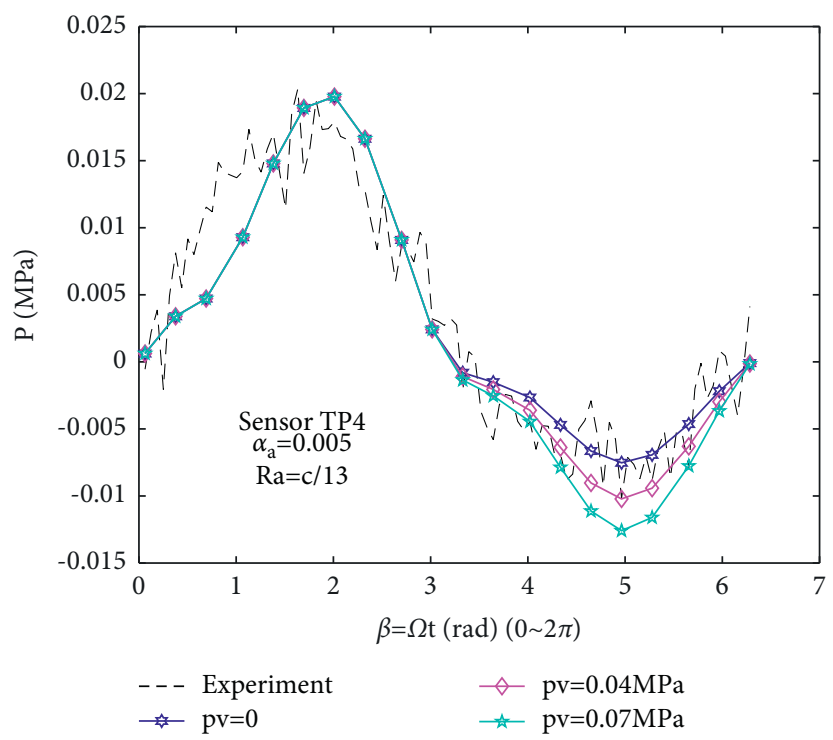

(b)

Figure 14: Comparison of experiment and simulation. (a) Different $\alpha_{a}$ and (b) different $p_{v}$.

$$
\left\{\begin{array}{l}
F_{r 1}=-\frac{\eta \mu \Omega R L_{f}^{3}}{C_{1}^{2}}\left[\frac{2 \varepsilon_{3}^{2}}{\left(1-\varepsilon_{3}^{2}\right)^{2}}\right], \\
F_{t 1}=-\frac{\eta \mu \Omega R L_{f}^{3}}{C_{1}^{2}}\left[\frac{\pi \varepsilon_{3}}{\left(1-\varepsilon_{3}^{2}\right)^{(3 / 2)}}\right] .
\end{array}\right.
$$

Equation (23) shows that the $F-\varepsilon$ curvature changes with $\mu$, but the shape of the curve does not change. The concept of equivalent viscosity was proposed by Diaz [38]. The equivalent radial viscosity $\mu_{\text {req }}$ and circumferential viscosity $\mu_{\text {teq }}$ are used to deal with the effect of cavitation. Following this idea, the inner film force of DCSFD considering cavitation can be expressed as 


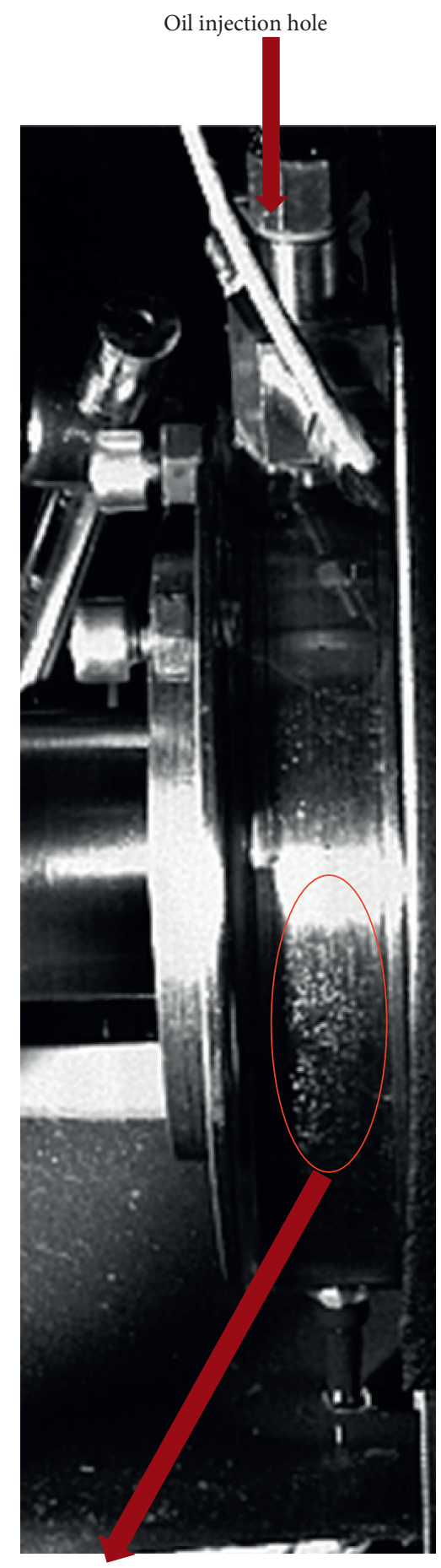

Vapor cavitation

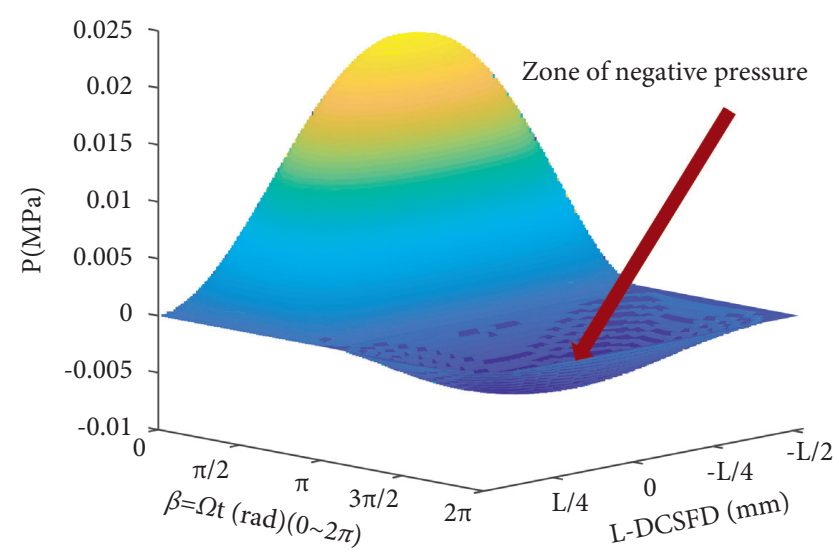

(a)

(b)

Figure 15: The zone of negative pressure. (a) Experiment. (b) Simulation. 


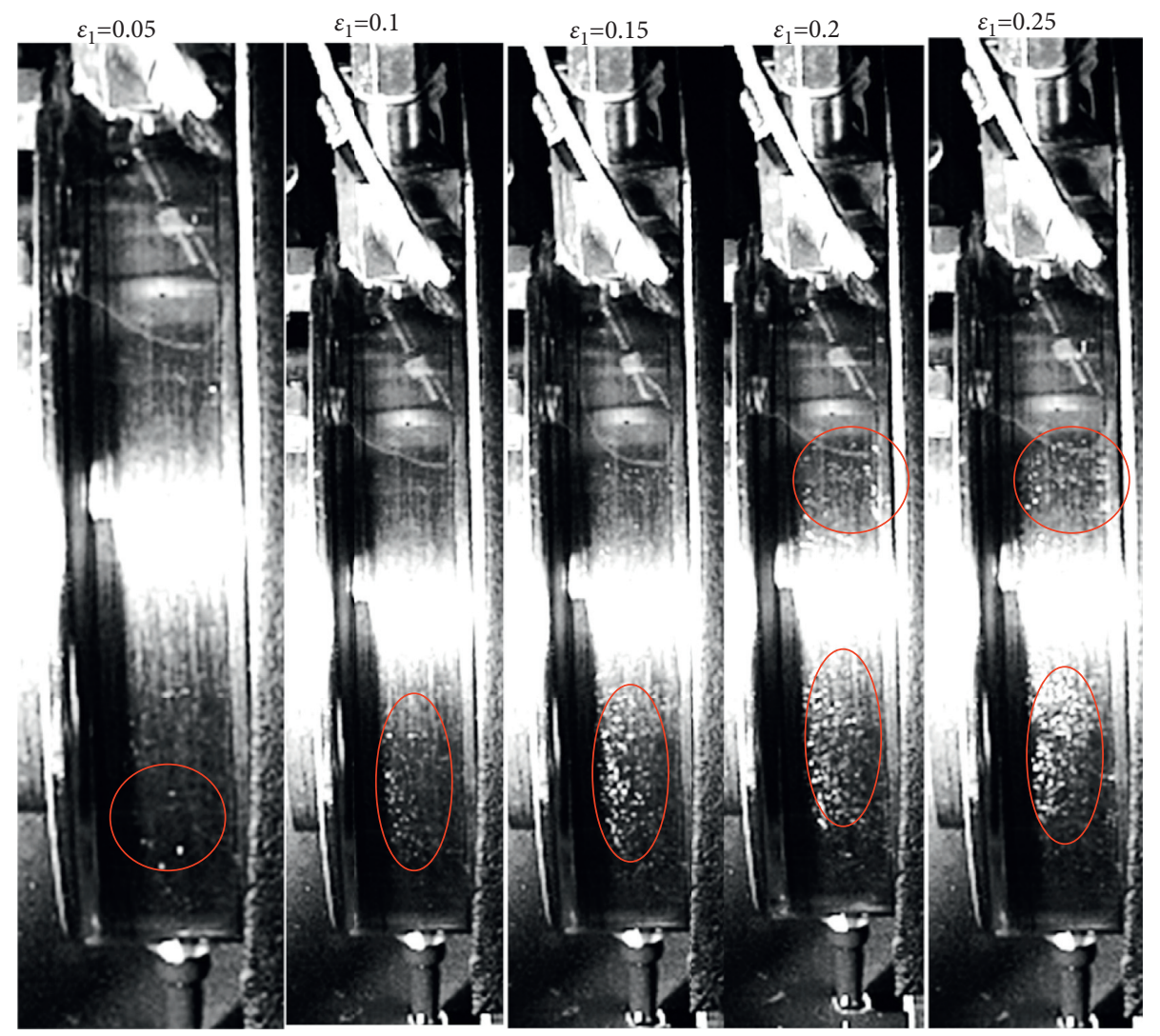

Figure 16: The cavitation of the outer film at different eccentricities ( $t=T / 4$, the red circle denotes the vapor cavitation).

$$
\left\{\begin{array}{l}
F_{r 1}=-\frac{\mu_{\text {req }} \eta \Omega R L_{f}^{3}}{C_{1}^{2}}\left[\frac{2 \varepsilon_{3}^{2}}{\left(1-\varepsilon_{3}^{2}\right)^{2}}\right], \\
F_{t 1}=-\frac{\mu_{\text {teq }} \eta \Omega R L_{f}^{3}}{C_{1}^{2}}\left[\frac{\pi \varepsilon_{3}}{\left(1-\varepsilon_{3}^{2}\right)^{3 / 2}}\right] .
\end{array}\right.
$$

While $\mu_{\text {req }}=0.3 \mu_{L}$ and $\mu_{\text {req }}=1.2 \mu_{L}$, the results of fitting and simulation have a good consistency, which are shown in Figure 7. Based on the equivalent viscosity, DCSFD modeling, considering cavitation effect, can be more efficient on the basis of guaranteed accuracy.

\section{Verification of Pressure Distribution and Cavitation Observation}

The bidirectional excitation test rig for DCSFD is shown in Figures 8-12.

In Figure 13, TP1_P, TP2_P, TP3_P, TP4_P, and TP5_P represent five pressure sensors evenly distributed in the lower semicircle of the housing with $45^{\circ}$ interval; TP6_P_inlet represents the pressure sensor for measuring the inlet pressure; TP7_T_inlet represents the temperature sensor for measuring the inlet oil temperature. TP8_ux and TP9_uy represent two eddy current displacement transducers in mutual perpendicular directions. TP10_Fx and TP11_Fy represent impendence heads measuring two excitation forces with mutually perpendicular directions. TP8_ux, TP10_Fx, and TP2_P are on the same diameter of the same housing center truncated circle. TP9_uy, TP11_Fy, and TP4_P are on the same diameter of the same housing center truncated circle. TP6_P_inlet and TP7_T_inlet are mounted on the top of the outer surface of the housing via a four-way valve. All sensors are mounted on the outer surface of the housing on the center truncated circle. The transparent housing is machined from Plexiglas glass, and the cavitation in the outer film of DCSFD is observed by i-speed7 high-speed camera.

5.1. Verification of Pressure Distribution. The pressure distributions obtained by experiment and simulation are shown in Figures 14 and 15. It is found that the results of the simulation are consistent with the experimental test. The proposed dynamic model is able to predict the width and peak of the zone of negative pressure. When $p_{v}=0, R_{a}=C_{1} / 13$, and $\alpha_{a}=0.005$, the numerical model most accurately described the distribution of the zone of negative pressure. Differently, the distribution of the zone of positive pressure is less affected by $p_{v}, R_{a}$, and $\alpha_{a}$, and the resulting curves are basically the same. Generally, the established DCSFD model, considering the effect of cavitation, is correct and effective.

A comparison of Figure 15(a) with Figure 15(b) shows that the cavitation is mainly located in the center of the zone of negative pressure along the width of the DCSFD, and a small number of bubbles are formed in the zone of positive pressure. 


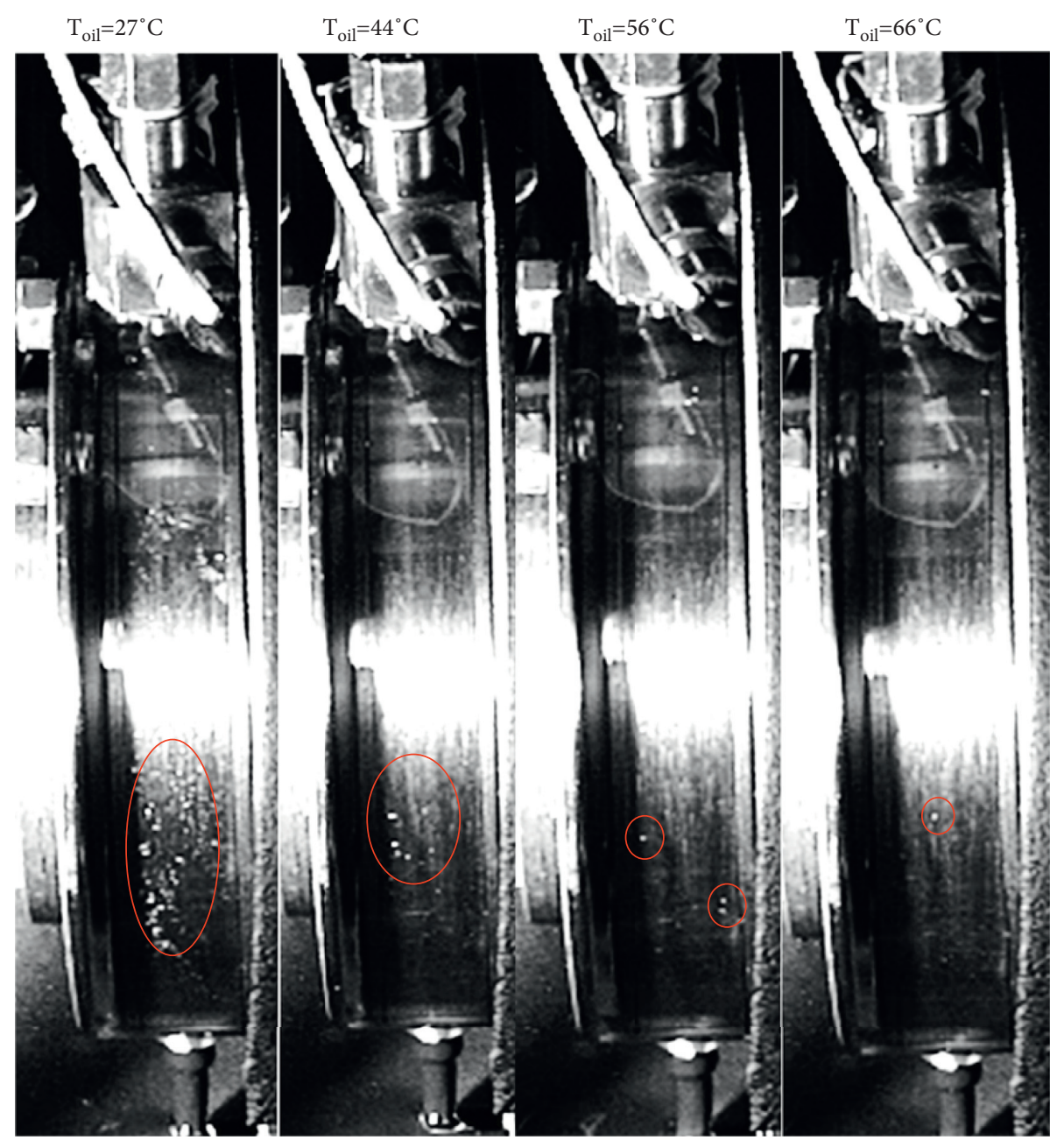

FIGURE 17: The cavitation of the outer film at different temperatures of oil ( $t=T / 4$, the red circle denotes the vapor cavitation).

5.2. Effect of Eccentricity on Cavitation. When the inlet pressure is $0.04 \mathrm{MPa}$, the temperature of oil is $27^{\circ} \mathrm{C}$, and the whirling frequency is $50 \mathrm{~Hz}$, the cavitation of the outer film is observed at different eccentricities. The results obtained by experimental observation are shown in Figure 16.

The area of negative pressure and number of bubbles increase with eccentricity. When $\varepsilon_{1}<0.2$, the cavitation occurs mainly in the lower half-circle away from the injection hole for oil, and when $\varepsilon_{1} \geq 0.2$, bubbles can be clearly observed in the upper half-circle area near the hole, but are distributed over a smaller area than in the lower half circle. Bubbles appear in the observation area throughout the DCSFD, indicating that the two-phase flow of oil and bubbles was relatively stable. When $\varepsilon_{1}>0.2$, a large number of bubbles gush out from the clearance between floating ring and end seals, which indicates that a large number of bubbles are formed in the inner film. The impact of the cavitation on the force of the inner film is hence reduced.

5.3. Effect of Oil Temperature on Cavitation. When the inlet pressure is $0.04 \mathrm{MPa}$, the inner eccentricity is 0.1 , and whirling frequency is $50 \mathrm{~Hz}$, the cavitation of the outer film is observed under different temperatures of oil. The results of observations are shown in Figure 17.

With an increase in the temperature of oil, the number of bubbles decreases sharply, and the area of cavitation almost disappears with only a few bubbles remaining. The cavitation is mainly concentrated in the lower circular area away from the injection hole of the oil. When the temperature of oil is $27^{\circ} \mathrm{C}$, the semicircle near the injection hole for oil also contains bubbles mainly from the clearance between floating ring and end seals. When the temperature increases to $44^{\circ} \mathrm{C}$, the bubbles in semicircle near the injection hole of oil disappear and become concentrated in the lower half of the circle. When the temperature of oil increases to $56^{\circ} \mathrm{C}$ or higher, only a few bubbles remain in the observation area and a large area of cavitation disappear.

5.4. Effect of Inlet Pressure on Cavitation. When the temperature of oil is $27^{\circ} \mathrm{C}$, inner eccentricity is 0.1 , and whirling frequency is $50 \mathrm{~Hz}$, the cavitation of the outer film is observed at different inlet pressures, and the result of observations are shown in Figure 18.

Obviously, the area of negative pressure decreases with increasing inlet pressure. When the inlet pressure is 


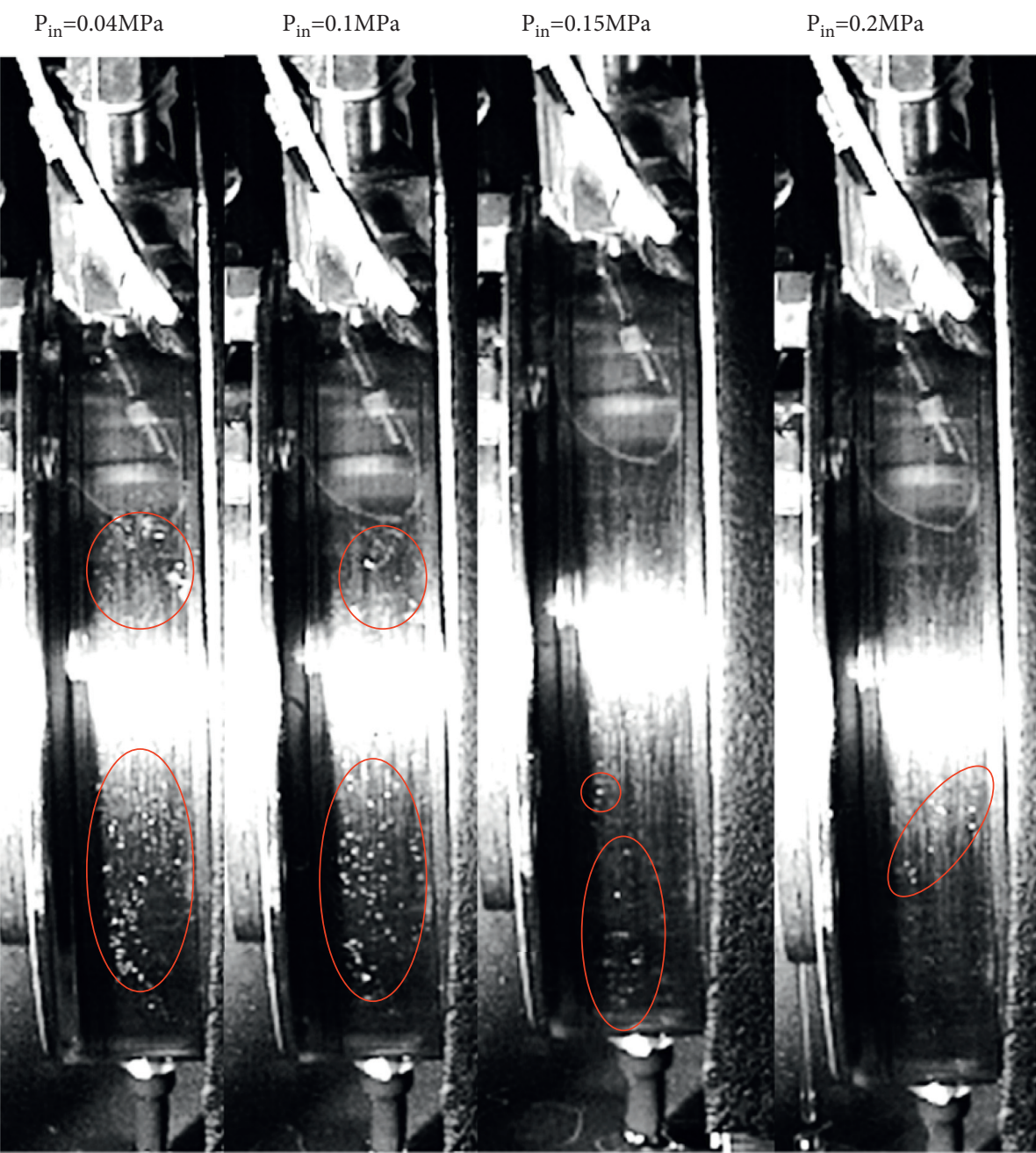

FIgURE 18: The cavitation of the outer film at different inlet pressures $(t=T / 4$, the red circle denotes the vapor cavitation).

$0.04 \mathrm{MPa}$ or $0.1 \mathrm{MPa}$, the area of bubbles appears not only in the lower circular areas but also in the upper circular areas near the oil injection hole. When the inlet pressure increases to $0.15 \mathrm{MPa}$ and above, the upper half of the area of the bubbles disappears, the area of cavitation shrinks to the lower half circle, and the number of bubbles decreases with inlet pressure. However, when the inlet pressure reaches $0.15 \mathrm{MPa}$, the radius of the bubbles increases significantly, but few of them remain in the area of positive pressure. When the inlet pressure reaches $0.2 \mathrm{MPa}$, few bubbles remain in the zone of the film ring. This indicates that with increase of inlet pressure, the DCSFD film will tend to become a $2 \pi$ film and the area of cavitation reduces gradually, but the radius of the bubbles increases. It is likely that while the inlet pressure increases, the speed of oil increases its dynamic pressure while reducing static pressure. This causes the increase in the radius of the bubbles.
5.5. Effect of Whirling Frequency on Cavitation. When the inlet pressure is $0.04 \mathrm{MPa}$, eccentricity is 0.1 , and oil temperature is $27^{\circ} \mathrm{C}$, the cavitation of the outer film can be observed and compared at different whirling frequencies. The results of the experiment are shown in Figure 19.

Under different frequencies of whirling, the area of distribution of the bubbles changes by little. Cavitation are gushing out of the clearance between end seals and floating ring at different frequencies.

The radius of cavitation increased with whirling frequency. This indicates that the whirling frequency had little effect on the area of cavitation, but increased the volume of the bubble. The reason behind this may be due to the fact that when the whirling frequency increases, the oil speed increases the dynamic pressure and decreases the static pressure, which eventually leads to a larger bubble radius. 


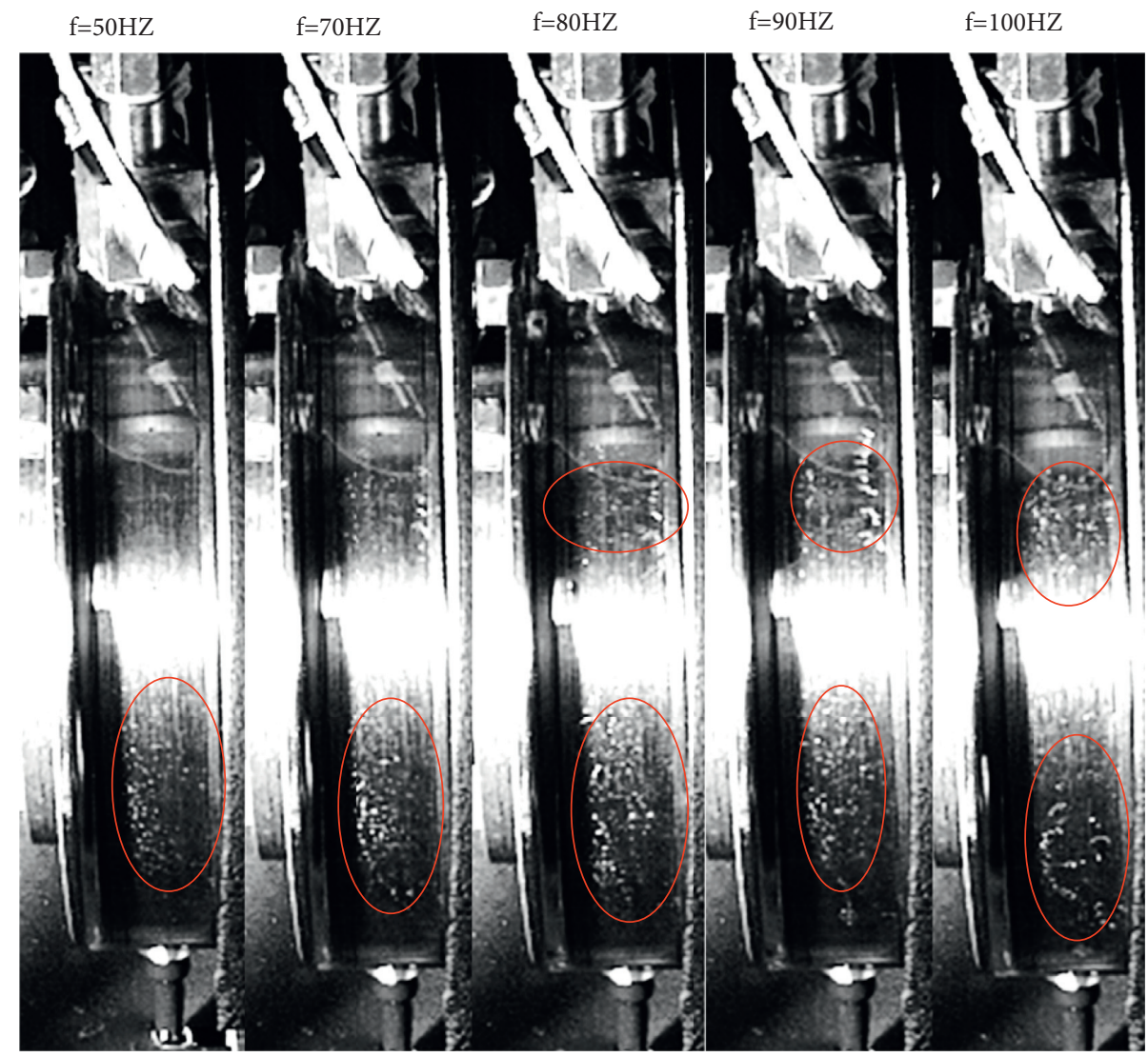

Figure 19: The cavitation of the outer film at different whirling frequencies $(t=T / 4$, the red circle denotes the vapor cavitation).

\section{Conclusions}

In this paper, a dynamic numerical model is developed for the DCSFD considering the effect of cavitation. The DCSFD model and cavitation model are solved simultaneously to obtain final pressure distribution of the inner and outer film. Some experiments are carried out; the experimental and numerical results of pressure distribution are in good agreement, which verifies the validity of the proposed numerical model. The effect of eccentricity, oil temperature, inlet pressure, and whirling frequency on cavitation is investigated by the experiment, and several useful conclusions are summarized as follows:

(1) Reasonable values of radius of the reference bubble $\left(R_{a}\right)$, vapor pressure $\left(p_{v}\right)$, and reference volume ratio $\left(\alpha_{a}\right)$ (for the DCSFD, in this paper, $R_{a}=C_{1} / 13, p_{v}=0$, and $\alpha_{a}=0.005$ ) can lead to more accurate descriptions of the DCSFD model for the positive and negative pressure zones than the $\pi$ film model.

(2) The influence of inlet pressure and eccentricity on cavitation is significant, and the cavitation of DCSFD is located far away from the oil injection hole. The area of cavitation increases with eccentricity. When the inlet pressure increases, the cavitation area decreases but the bubble volume increases. There will be vapor cavitation near the oil injection hole while the eccentricity reaches and exceeds 0.2 ;
(3) The area of cavitation and volume of bubble decreases with oil temperature. When the temperature of oil increased to $56^{\circ} \mathrm{C}$ or above, the area of cavitation nearly disappeared and only a few bubbles remained.

(4) When there are much cavitation in the inner film, due to the pressure difference between the inner and outer film, the bubbles will flow into the outer film through the clearance between the end seal and the floating ring, which will reduce the influence of cavitation on the damping characteristics of DCSFD.

\section{Data Availability}

The data used to support the findings of the study are available from the corresponding author upon request.

\section{Conflicts of Interest}

The authors declare that they have no conflicts of interest.

\section{Acknowledgments}

The authors thank the National Natural Science Foundation of China (fund serial no. 51775266), the National Planned Major S\&T Project (project no. 2017-IV-0008-0045), and the Key Laboratory of Aero Engine Vibration Technology of Aero Engine Corporation of China for their support. 


\section{References}

[1] H. Chen, L. Hou, Y. Chen, and R. Yang, "Dynamic characteristics of flexible rotor with squeeze film damper excited by two frequencies," Nonlinear Dynamics, vol. 87, no. 4, pp. 1-19, 2016.

[2] H. Chen, L. Hou, and Y. Chen, "Bifurcation analysis of a rigidrotor squeeze film damper system with unsymmetrical stiffness supports," Archive of Applied Mechanics, vol. 87, no. 8, pp. 1347-1364, 2017.

[3] J. A. A. Tichy, "Study of the effect of fluid inertia and end leakage in the finite squeeze film damper," Journal of Tribology, vol. 109, no. 1, pp. 1653-1675, 1987.

[4] A. El-Shafei and S. H. Crandall, "Fluid inertia forces in squeeze film dampers," in Proceedings of the ASME Conference on Mechanical Vibration \& Noise, Miami, FL, USA, March 1991.

[5] H. Chen, Y. Chen, L. Hou, and Z. Li, "Bifurcation analysis of rotor-squeeze film damper system with fluid inertia," Mechanism and Machine Theory, vol. 81, no. 1, pp. 129-139, 2014.

[6] X. Wang, Z. Han, Q. Ding, and W. Zhang, "Influence of fluid inertia on dynamic characteristics of elastic ring squeeze film damper-rotor system," Hangkong Dongli Xuebao/Journal of Aerospace Power, vol. 33, no. 12, pp. 2981-2990, 2018.

[7] S. Hamzehlouia and K. Behdinan, "Squeeze film dampers supporting high-speed rotors: fluid inertia effects," Proceedings of the Institution of Mechanical Engineers Part J Journal of Engineering Tribology ARCHIVE, vol. 234, no. 1, pp. 18-34, 2019.

[8] K. H. Groves and P. Bonello, "Improved identification of squeeze-film damper models for aeroengine vibration analysis," Tribology International, vol. 43, no. 9, pp. 1639-1649, 2010.

[9] T. Fan and K. Behdinan, "Investigation into the effect of piston ring seals on an integrated squeeze film damper model," Journal of Mechanical Science and Technology, vol. 33, no. 2, pp. 559-569, 2019.

[10] X. Chen, X. Gan, and G. Ren, "Nonlinear responses and bifurcations of a rotor-bearing system supported by squeezefilm damper with retainer spring subjected to base excitations," Nonlinear Dynamics, vol. 102, pp. 1-35, 2020.

[11] X. Lu, L. S. Andres, B. Koo, and S. Tran, "On the effect of the gap of end seals on force coefficients of a test integral squeeze film damper: experiments and predictions," Journal of Engineering for Gas Turbines and Power, vol. 143, no. 1, 2020.

[12] D. P. Fleming, "Dual clearance squeeze film damper for high load conditions," Journal of Tribology, vol. 107, no. 2, pp. 274-278, 1985.

[13] L. Moraru, T. G. Keith, F. Dimofte, S. Cioc, and D. P. Fleming, "Dynamic modeling of a dual clearance squeeze film damperpart I: test rig and dynamic model with one damper," Tribology Transactions, vol. 46, no. 2, pp. 170-178, 2003.

[14] L. Moraru, T. G. Keith, F. Dimofte, S. Cioc, and D. P. Fleming, "Dynamic modeling of a dual clearance squeeze film damper. part II,” Tribology Transactions, vol. 49, no. 4, pp. 611-620, 2006.

[15] L. Moraru, T. G. Keith, F. Dimofte, S. Cioc, and D. P. Fleming, "A study of a dual clearance squeeze film damper," Journal of Tribology, vol. 107, no. 2, pp. 274-279, 2009.

[16] L. Moraru, T. G. Keith, F. Dimofte, S. Cioc, N. Ene, and D. P. Fleming, "A dynamic analysis of a dual clearance squeeze film damper," in Proceedings of the STLE/ASME 2010
International Joint Tribology Conference, San Francisco, CA, USA, October 2010.

[17] M. A. Rezvani and E. J. Hahn, "Floating ring squeeze film damper: theoretical analysis," Tribology international, vol. 33, no. 3-4, pp. 249-258, 2000.

[18] H. L. Zhou, G. H. Luo, G. Chen, and H. T. Tian, "Two dynamic models of dual clearance squeeze film damper and their verification," Tribology International, vol. 66, no. 2013, pp. 187-193, 2013.

[19] H.-l. Zhou, G.-h. Luo, G. Chen, and F. Wang, "Analysis of the nonlinear dynamic response of a rotor supported on ball bearings with floating-ring squeeze film dampers," Mechanism and Machine Theory, vol. 59, no. 4, pp. 65-77, 2013.

[20] D. Hibner and P. Bansal, "Effect of fluid compressibility on viscous damper characteristics," in Proceedings of the Conference on the Stability and Dynamic Response of Rotors with Squee, Charlottesville, VA, USA, May 1979.

[21] N. S. Feng and E. J. Hahn, "Cavitation effects on squeeze-film damper performance," ASLE Transactions, vol. 29, no. 3, pp. 353-360, 1986.

[22] S. Y. Jung, L. A. San Andres, and J. M. Vance, "Measurements of pressure distributions and force coefficients in a squeeze film damper part I: fully open ended configuration," Tribology Transactions, vol. 34, no. 3, pp. 375-382, 1991.

[23] S. Y. Jung, L. A. San Andres, and J. M. Vance, "Measurements of pressure distributions and force coefficients in a squeeze film damper part II: partially sealed configuration," Tribology Transactions, vol. 34, no. 3, pp. 383-388, 1991.

[24] J. Kodama, A. Mori, and N. Tagawa, "Study of submerged squeeze film damper with a centering spring. cavitation and pressure distribution," Transactions of the Japan Society of Mechanical Engineers Series C, vol. 66, no. 643, pp. 979-985, 2000.

[25] P. Bonello, M. J. Brennan, and R. Holmes, "A study of the nonlinear interaction between an eccentric squeeze film damper and an unbalanced flexible rotor," Journal of Engineering for Gas Turbines and Power, vol. 126, no. 4, pp. 855-866, 2004.

[26] C. Xing, M. J. Braun, and H. Li, “A Three-dimensional NavierStokes-based numerical model for squeeze film dampers. Part 2: effects of gaseous cavitation on the behavior of the squeeze film damper," Tribology Transactions, vol. 52, pp. 695-705, 2009.

[27] C. Xing, M. J. Braun, and H. Li, “A three-dimensional NavierStokes-based numerical model for squeeze-film dampers. Part 1: effects of gaseous cavitation on pressure distribution and damping coefficients without consideration of inertia," Tribology Transactions, vol. 52, pp. 680-694, 2009.

[28] C. Xing, M. J. Braun, and H. Li, "Damping and added mass coefficients for a squeeze film damper using the full 3-D Navier-Stokes equation," Tribology International, vol. 43, no. 3, pp. 654-666, 2010.

[29] S. -Y. Jung, "The effect of oil supply pressure on the performance of vapor cavitated short squeeze film damper," Journal of the KSTLE, vol. 24, no. 3, pp. 147-153, 2008.

[30] T. H. Méndez, M. A. Ciaccia, S. E. Díaz, and J. E. Torres, "On the numerical prediction of finite length squeeze film dampers performance with free air entrainment," Journal of Engineering for Gas Turbines\&Power.vol. 132, no. 1, pp. 31-39, 2008.

[31] M. Arghir and O. Bonneau, "Evaluation of rayleigh-plesset equation based cavitation models for squeeze film damper," Journal of Tribology, vol. 131, no. 2, pp. 307-309, 2009. 
[32] A. A. Younan, J. Cao, T. W. Dimond, and P. E. Allaire, "Nonlinear analysis of squeeze film damper with entrained air in rotordynamic systems," Tribology Transactions, vol. 54, no. 1, pp. 132-144, 2010.

[33] H. Heidari and M. Ashkooh, "The influence of asymmetry in centralizing spring of squeeze film damper on stability and bifurcation of rigid rotor response," Alexandria Engineering Journal, vol. 55, no. 4, pp. 3321-3330, 2016.

[34] J. Gehannin, M. Arghir, and O. Bonneau, "Evaluation of rayleigh-plesset equation based cavitation models for squeeze film damper," Journal of Tribology, vol. 131, no. 2, pp. 307309, 2009.

[35] M. Laurentiu, "A brief discussion regarding types of cavitation in squeeze film dampers and cavitation effects," INCAS Bulletin, vol. 9, no. 1, pp. 71-76, 2017.

[36] T. Fan and K. Behdinan, "The evaluation of linear complementarity problem method in modeling the fluid cavitation for squeeze film damper with off-centered whirling motion," Lubricants, vol. 5, no. 46, pp. 1-13, 2017.

[37] C. E. B Rennen, Cavitation and Bubble Dynamics, Cambridge University Press, Cambridge, UK, 2013.

[38] S. E. Diaz, The Effect of Air Entrapment on the Performance of Squeeze Film Dampers: Experiments and Analysis, Texas A\&M University, Austin, TX, USA, 1999.

[39] L. Della Pietra, "Analytical and experimental investigation of squeeze-film dampers executing circular orbits," Meccanina, vol. 35, no. 1, pp. 133-157, 2000. 